\section{External limiting membrane and visual outcome in macular hole repair: spectral domain OCT analysis}

G Landa ${ }^{1,2}$, RC Gentile ${ }^{1,2}$, PMT Garcia ${ }^{1,2}$, TO Muldoon ${ }^{1,2}$ and RB Rosen ${ }^{1,2}$ restoration of the photoreceptor layer and for predicting a successful visual outcome following $\mathrm{MH}$ repair.

Eye (2012) 26, 61-69; doi:10.1038/eye.2011.237; published online 7 October 2011

Keywords: external limiting membrane; macular hole repair; spectral domain OCT

\section{Introduction}

Anatomical and visual outcomes of macular hole $(\mathrm{MH})$ surgery have significantly improved in recent years. Spectral domain optical coherence tomography (SD-OCT), with an axial resolution of $\sim 5 \mu \mathrm{m}$, has substantially improved the visualization of foveal microstructures of the outer retina, revealing distinct hyper-reflective lines, corresponding to the external limiting membrane (ELM), the inner segment-outer segment (IS-OS) junction layer, the outer segment layer, and retinal pigment epithelium. The IS-OS junction hyperreflective line appears to coincide with the isthmus between the inner and outer segments of the photoreceptors. Recent reports have demonstrated that the postoperative status of the IS-OS layer significantly correlates with the visual outcome of $\mathrm{MH}$ surgery. ${ }^{1-5}$ Specifically, disruptions in this layer were associated with poorer visual outcomes. ${ }^{1-5}$

The ELM appears as another hyper-reflective landmark in the outer retina. Although less prominent, the ELM line is distinctive, located just above the IS-OS junction hyper-reflective line. Photoreceptor cell bodies containing the nuclei and the apical processes of Müller cells are connected by a row of zonular adherentes that collectively form the ELM. ${ }^{6,7}$ Recent findings in eyes following retinal detachment (RD)
${ }^{1}$ Retina Center, Department of Ophthalmology, New York Eye and Ear Infirmary, New York, NY, USA

${ }^{2}$ Department of Ophthalmology, New York Medical College, Valhalla, NY, USA

Correspondence: RB Rosen, Retina Center, Department of Ophthalmology, New York Eye and Ear Infirmary, 310 East 14th Street, New York City, NY 10003, USA

Tel: + 1212979 4288;

Fax: + 12129794268 .

E-mail: rrosen@nyee.edu

Received: 13 December 2010

Accepted in revised form: 19 August 2011 Published online: 7 October 2011 
repair have shown that combined disruptions of ELM and IS-OS result in worse visual outcomes compared with eyes with isolated IS-OS disruptions. The integrity of the ELM appears to have a critical role in restoration of the photoreceptor microstructures. ${ }^{8,9}$ Several clinicopathological studies of $\mathrm{MH}$ repair have suggested that anatomical repair of full-thickness MHs requires proliferation of glial cells, believed to be originated from Müller cells. ${ }^{10-13}$ Madreperla et $a l^{11}$ demonstrated the sealing of a break in the ELM by Müller cell processes in an eye with a stage III MH.

We postulate that successful reformation of zonular adherentes between photoreceptors' inner segments and Müller cells, evidenced by a continuous ELM line on SD-OCT, is critical for the restoration of the photoreceptor layer and for a better visual outcome following $\mathrm{MH}$ repair.

The purpose of this study was to examine the SD-OCT images of repaired MHs and analyze the relationship between the restoration of the integrity of ELM and IS-OS junction layers and subsequent visual outcomes.

\section{Materials and methods}

A retrospective survey of consecutive patients following $\mathrm{MH}$ repair (stage 2-4) was conducted. The study was approved by the Institutional Review Board of the New York Eye and Ear Infirmary.

Medical charts of consecutive cases of MH surgery, managed by pars plana vitrectomy and gas tamponade, were identified and reviewed. A standard surgical procedure of $\mathrm{MH}$ repair was performed in all the cases, using the same surgical technique by members of the Retina service with similar surgical experience. The surgical technique consisted of a standard three-port pars plana vitrectomy with removal of the posterior cortical vitreous and creation of posterior hyaloidal detachment when necessary. The posterior hyaloid was detached at the optic disc by aspiration using either a soft-tipped cannula or a vitrectomy probe. In the majority of cases, an indocyanine green dye-assisted peeling of the internal limiting membrane (ILM), in addition to the standard vitrectomy, was performed. Indocyanine green dye $(0.5 \%, 5 \mathrm{mg} / \mathrm{ml})$ was used to stain the ILM. The edge of the ILM was elevated by using a diamond-dusted silicone brush or intraocular forceps. The elevated ILM was peeled from the retina using intraocular forceps in a continuous curvilinear maculorhexis manner. Following fluid-air exchange, the globe was filled with a mixture of gas (12-14\% of perfluoropropane (C3F8) or $20 \%$ sulphur hexafluoride $\left(\mathrm{SF}_{6}\right)$ ) and air. Patients were instructed to maintain a prone position for at least 7 days.

High-resolution SD-OCT (OPKO/OTI, Miami, FL, USA) was used to image the foveal microstructural characteristics of the eyes studied preoperatively and postoperatively (at 6 weeks $(+/-1$ week) and 6 months $(+/-1$ month $)$ ).

At 6 weeks postoperatively all eyes were evaluated to determine the success of $\mathrm{MH}$ closure. If a normal anatomic profile of the fovea was not formed or $\mathrm{MH}$ edges were still open or subretinal fluid was present, those eyes were excluded from further analysis. Thus, only eyes with successfully closed MHs at 6 weeks postoperative examination were subjected to further analysis.

The status of the line corresponding to the ELM layer and the line corresponding to the photoreceptor IS-OS junction layer were evaluated on SD-OCT scans performed at 6 weeks $(+/-1$ week) and 6 months (+/ -1 month) after MH surgery. The corresponding cross-sectional scans through the thinnest area of the central fovea were compared. Based on the status of ELM and IS-OS layers in the SD-OCT scans at 6-week followup examination, eyes were divided into the following groups: (1) ELM continuous and IS-OS continuous $\left(\right.$ ELM $\left.^{\mathrm{c}} / \mathrm{IS}-\mathrm{OS}^{\mathrm{c}}\right),(2)$ ELM discontinuous and IS-OS discontinuous $\left(E^{2} M^{\mathrm{d}} / \mathrm{IS}_{-} \mathrm{OS}^{\mathrm{d}}\right)$, (3) ELM continuous and IS-OS discontinuous (ELM ${ }^{\mathrm{c}} / \mathrm{IS}^{-} \mathrm{OS}^{\mathrm{d}}$ ), and (4) ELM discontinuous and IS-OS continuous $\left(\mathrm{ELM}^{\mathrm{d}} / \mathrm{IS}-\mathrm{OS}^{\mathrm{c}}\right)$.

Two graders independently analyzed the SD-OCT images, and then ultimately reached a consensus.

The demographic and preoperative clinical characteristics of the groups are summarized in Table 1. The baseline and clinical characteristics collected included the following parameters: age, gender, $\mathrm{MH}$ staging, MH duration, preoperative lens status, preoperative best-corrected visual acuity (BCVA), and surgical parameters. $\mathrm{MH}$ duration was defined as the interval between the beginning of visual symptoms such as metamorphopsia, blurring, or scotoma, and the date of surgery. BCVA was measured using Snellen visual acuity charts preoperatively and postoperatively at 6-week and 6-month follow-up visits. Measured BCVA values were converted to the logarithm of the minimal angle of resolution scale for further analysis. Logarithms of the minimal angle of resolution values of 2.0 and 3.0 were assigned for counting fingers and hand motions vision, respectively. ${ }^{14}$

The primary outcome measures were BCVA, and status of the ELM and IS-OS at 6 weeks and 6 months postoperatively.

\section{Statistical analysis}

Statistical analysis was carried out using SPSS software (17.0; SPSS Inc., Chicago, IL, USA). Friedman's test was used to compare parameters between the groups. Wilcoxon's signed-ranks test was used to compare 
Table 1 Demographic and preoperative clinical characteristics of the patients

\begin{tabular}{|c|c|c|c|c|}
\hline Variable & $E L M^{c} / I S-O S^{c}$ & $E L M^{c} / I S-O S^{d}$ & $E L M^{d} / I S-O S^{d}$ & P-value \\
\hline Number of eyes $(n)$ & 7 & 29 & 20 & \\
\hline Age (years) (mean $\pm \mathrm{SD})$ & $69.1 \pm 7.6$ & $67.4 \pm 6.1$ & $65.8 \pm 6.7$ & 0.57 \\
\hline Gender (females/males) & $6 / 1$ & $22 / 7$ & $17 / 3$ & 0.36 \\
\hline Macular hole stage, n (\%) & & & & 0.14 \\
\hline Stage 2 & $2(28.6)$ & $2(6.9)$ & $2(10.0)$ & \\
\hline Stage 3 & $3(42.8)$ & $19(65.5)$ & $11(55.0)$ & \\
\hline Stage 4 & $2(28.6)$ & $8(28.6)$ & $7(35.0)$ & \\
\hline Macular hole duration, $\mathrm{n}(\%)$ & & & & 0.74 \\
\hline Less than six months & $4(57.2)$ & $11(37.9)$ & $7(35.0)$ & \\
\hline Six months or greater & $3(42.8)$ & $13(44.8)$ & $8(40.0)$ & \\
\hline Unclear by history & 0 & $5(17.3)$ & $5(25.0)$ & \\
\hline Preoperative lens status, n (\%) & & & & 0.13 \\
\hline Phakic, no significant cataract & $3(42.8)$ & $4(13.8)$ & $4(20.0)$ & \\
\hline Phakic, significant cataract & $3(42.8)$ & $13(44.8)$ & $6(30.0)$ & \\
\hline IOL & $1(14.4)$ & $12(41.4)$ & $10(50.0)$ & \\
\hline \multicolumn{5}{|l|}{ Surgery } \\
\hline ILM peeling (yes/no) & $6 / 1$ & $26 / 3$ & $18 / 2$ & 0.37 \\
\hline Use of long-acting gas $\left(\mathrm{SF}_{6} / \mathrm{C}_{3} \mathrm{~F}_{8}\right)$ & $2 / 5$ & $7 / 22$ & $8 / 12$ & 0.22 \\
\hline \multicolumn{5}{|l|}{ Preoperative $B C V A$} \\
\hline $\operatorname{LogMAR}($ mean $\pm \mathrm{SD})$ & $0.88 \pm 0.56$ & $0.89 \pm 0.37$ & $0.92 \pm 0.53$ & 0.31 \\
\hline Snellen equivalent (mean; range) & $20 / 152$ & $20 / 155$ & $20 / 166$ & \\
\hline
\end{tabular}

Abbreviation: ELM, external limiting membrane; IS-OS, photoreceptor inner and outer segments junction; BCVA, best-corrected visual acuity; logMAR, logarithm of the minimum angle of resolution; ILM, internal limiting membrane; SD, standard deviation; IOL, intraocular lens.

$\mathrm{ELM}^{\mathrm{c}} / \mathrm{IS}^{\mathrm{O}} \mathrm{OS}^{\mathrm{c}}$ - continuous ELM and continuous IS-OS.

$\mathrm{ELM}^{\mathrm{c}} / \mathrm{IS}-\mathrm{OS}^{\mathrm{d}}$ - continuous ELM and discontinuous IS-OS.

$\mathrm{ELM}^{\mathrm{d}} /$ IS-OS $^{\mathrm{d}}$ - discontinuous ELM and discontinuous IS-OS.

pre- and postoperative BCVA for each group. The MannWhitney $U$ test was used for BCVA comparison between the two specific groups. Categorical variables were analyzed using Fisher's exact test. $P$-values $<0.05$ were considered to be statistically significant.

\section{Results}

Of 76 cases reviewed, 62 eyes of 62 patients who underwent idiopathic $\mathrm{MH}$ repair using vitrectomy with gas tamponade were included.

Fourteen eyes were excluded for various reasons: poor quality of SD-OCT scans (five eyes), traumatic MH (three eyes), optic pit (one eye), combined RD and MH at presentation (one eye), use of silicone oil for intraocular tamponade (two eyes), and previous MH surgery (two eyes).

At 6-weeks postoperative SD-OCT examination, a successful closure of $\mathrm{MH}$ with restoration of normal foveal contour was achieved in $90.3 \%$ (56 out of 62) of the eyes. Of 56 eyes with successful MH closure: 0 eyes showed the combination of a disrupted ELM and a continuous IS-OS junction layer; 7 eyes (12.5\%) demonstrated continuity of both ELM and IS-OS layers (ELM $^{\mathrm{c}} /$ IS-OS ${ }^{\mathrm{c}}$ group); 29 eyes $(51.8 \%)$ showed the combination of continuous ELM and discontinuous IS-OS layers (ELM ${ }^{\mathrm{c}} / \mathrm{IS}^{-} \mathrm{OS}^{\mathrm{d}}$ group); and in 20 eyes $(35.7 \%)$ discontinuity in both layers was observed $\left(\mathrm{ELM}^{\mathrm{d}} / \mathrm{IS}-\mathrm{OS}^{\mathrm{d}}\right.$ group) (Figure 1).

There were no significant differences in the baseline characteristics of age, gender, $\mathrm{MH}$ staging and duration, preoperative lens status, preoperative BCVA, or surgical parameters between the three groups (Table 1).

The mean preoperative and postoperative BCVA $(\operatorname{logMAR} \pm \mathrm{SD})$ at 6 weeks and 6 months were $0.88 \pm 0.56$, $0.49 \pm 0.12$, and $0.27 \pm 0.17$ in the ELM ${ }^{\mathrm{c}} / \mathrm{IS}-\mathrm{OS}^{\mathrm{c}}$ group, $0.89 \pm 0.37,0.58 \pm 0.20$, and $0.33 \pm 0.20$ in the ELM ${ }^{\mathrm{c}} /$ IS-OS ${ }^{\mathrm{d}}$ group, and $0.92 \pm 0.53,0.70 \pm 0.26$, and $0.60 \pm 0.25$ in the $\mathrm{ELM}^{\mathrm{d}} / \mathrm{IS}^{-} \mathrm{OS}^{\mathrm{d}}$ group, respectively. Friedman's test showed that the ELM ${ }^{\mathrm{d}} /$ IS-OS $^{\mathrm{d}}$ group had the lowest visual gain both at 6 weeks and 6 months, however; only at 6 months, was there a statistically significant difference between the three groups $(P=0.03)$ (Table 2 and Figure 2)

The majority of the patients in this study demonstrated improved visual acuities postoperatively. The differences 

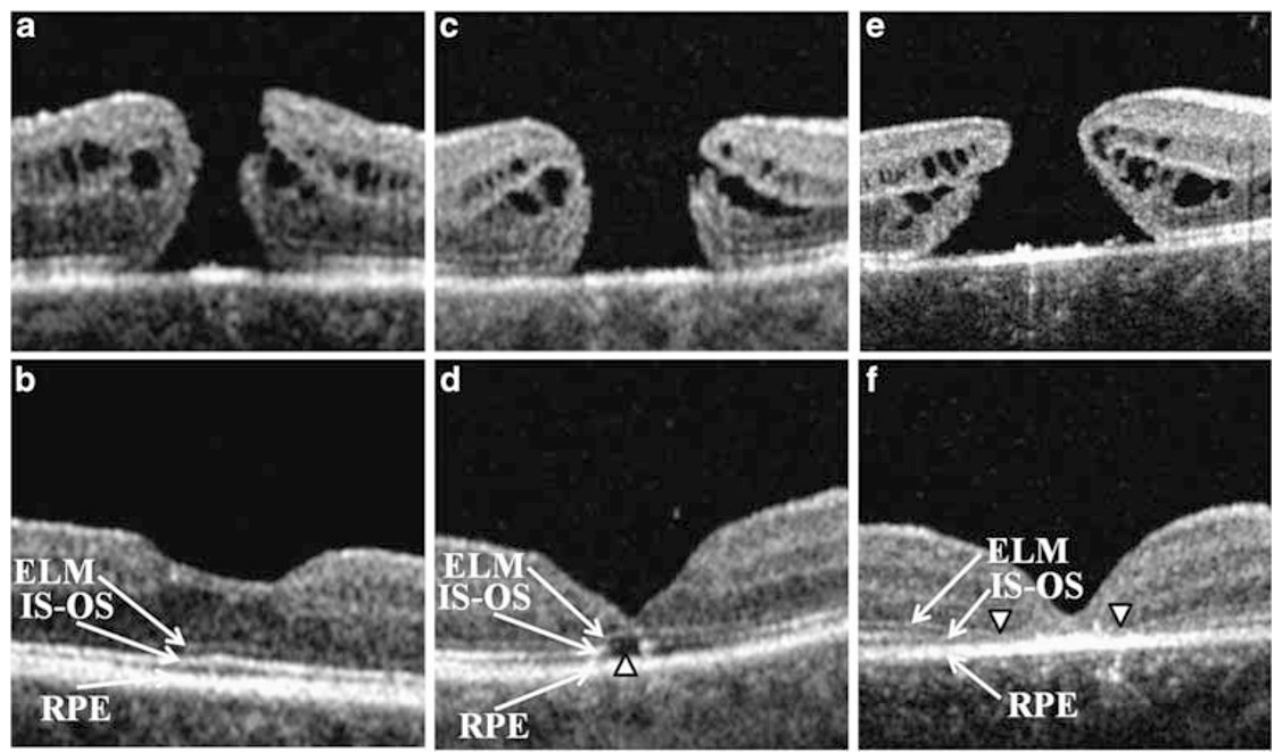

Figure 1 Representative SD-OCT images of the three groups. Preoperative (upper images) and postoperative images at 6 weeks after the macular hole repair (lower images). SD-OCT, spectral domain optical coherence tomography; ELM, external limiting membrane; IS-OS, inner segment-outer segment junction layer; RPE, retinal pigment epithelium. First group (a, b) - ELM continuous and IS-OS continuous $\left(\mathrm{ELM}^{\mathrm{c}} / \mathrm{IS}-\mathrm{OS}^{\mathrm{c}}\right)$, second group (c, d) -ELM continuous and IS-OS discontinuous (ELM $/ \mathrm{IS}^{\mathrm{O}} \mathrm{OS}^{\mathrm{d}}$ ), and third group $(\mathrm{e}, \mathrm{f})-$ ELM discontinuous and IS-OS discontinuous $\left(\mathrm{ELM}^{\mathrm{d}} / \mathrm{IS}-\mathrm{OS}{ }^{\mathrm{d}}\right)$. Arrowheads indicate disruptions in IS-OS (d) and ELM (f).

Table 2 Preoperative and postoperative mean best-corrected visual acuities at 6 weeks and 6 months after the surgery in the studied groups

\begin{tabular}{|c|c|c|c|c|}
\hline Variable & $E L M^{c} / I S-O S^{c}$ & $E L M^{c} / I S-O S^{d}$ & $E L M^{d} / I S-O S^{d}$ & P-value \\
\hline Number of eyes $(n)$ & 7 & 29 & 20 & \\
\hline \multicolumn{5}{|l|}{ Preoperative BCVA } \\
\hline $\operatorname{LogMAR}($ mean $\pm \mathrm{SD})$ & $0.88 \pm 0.56$ & $0.89 \pm 0.37$ & $0.92 \pm 0.53$ & 0.31 \\
\hline Snellen equivalent (mean) & $20 / 152$ & $20 / 155$ & $20 / 166$ & \\
\hline \multicolumn{5}{|l|}{ Postoperative BCVA at 6 weeks } \\
\hline $\begin{array}{l}\text { Interval between the surgery and postoperative } \\
\text { examination, weeks (mean } \pm \text { SD) }\end{array}$ & $5.8 \pm 1.0$ & $6.1 \pm 0.8$ & $6.0 \pm 0.8$ & 0.23 \\
\hline $\operatorname{LogMAR}($ mean $\pm \mathrm{SD})$ & $0.49 \pm 0.12$ & $0.58 \pm 0.20$ & $0.70 \pm 0.26$ & 0.08 \\
\hline Snellen equivalent (mean) & $20 / 62$ & $20 / 76$ & $20 / 100$ & \\
\hline \multicolumn{5}{|l|}{ Postoperative BCVA at 6 months } \\
\hline $\begin{array}{l}\text { Interval between the surgery and postoperative } \\
\text { examination, months (mean } \pm \text { SD) }\end{array}$ & $6.3 \pm 0.9$ & $5.9 \pm 0.9$ & $6.1 \pm 0.9$ & 0.82 \\
\hline LogMAR $($ mean \pm SD) & $0.27 \pm 0.17$ & $0.33 \pm 0.20$ & $0.60 \pm 0.25$ & 0.03 \\
\hline Snellen equivalent (mean) & $20 / 37$ & $20 / 43$ & $20 / 80$ & \\
\hline Improvement of $\geq 2$ lines, $n(\%)$ & $6 / 7(85.7)$ & $25 / 29(86.2)$ & $9 / 20(45)$ & 0.01 \\
\hline Continuous IS-OS at 6 months, $n(\%)$ & $7(100)$ & $15(51.7)$ & $1(5.0)$ & 0.001 \\
\hline
\end{tabular}

Abbreviations: ELM, external limiting membrane; IS-OS, photoreceptor inner and outer segments junction; BCVA, best-corrected visual acuity; logMAR, logarithm of the minimum angle of resolution; SD, standard deviation.

$\mathrm{ELM}^{\mathrm{c}} / \mathrm{IS}^{\mathrm{OOS}}{ }^{\mathrm{c}}$ - continuous ELM and continuous IS-OS.

ELM $^{\mathrm{c}} / \mathrm{IS}_{\mathrm{O}} \mathrm{OS}^{\mathrm{d}}$ - continuous ELM and discontinuous IS-OS.

$\mathrm{ELM}^{\mathrm{d}} / \mathrm{IS}_{-} \mathrm{OS}^{\mathrm{d}}$-discontinuous ELM and discontinuous IS-OS.

between preoperative BCVA and postoperative BCVA values were statistically significant both at 6 weeks $(P=0.028$, Wilcoxon's signed-ranks test $)$ and at 6 months $(P=0.005)$ in the ELM ${ }^{\mathrm{c}} / \mathrm{IS}^{-\mathrm{OS}^{\mathrm{c}}}$ group.
The corresponding values in the ELM ${ }^{\mathrm{c}} / \mathrm{IS}_{-} \mathrm{OS}^{\mathrm{d}}$ group were also found to be statistically significant both at 6 weeks and at 6 months $(P<0.001$ and $<0.001$, respectively). In the $\mathrm{ELM}^{\mathrm{d}} / \mathrm{IS}_{-}-\mathrm{OS}^{\mathrm{d}}$ group, the difference 
between preoperative BCVA and postoperative BCVA did not reach statistical significance at 6 weeks $(P=0.054)$, but did so at 6 months $(P=0.008)$.

When we analyzed the differences between the $\mathrm{ELM}^{\mathrm{c}} / \mathrm{IS}^{-\mathrm{OS}^{\mathrm{c}}}$ and ELM ${ }^{\mathrm{c}} / \mathrm{IS}-\mathrm{OS}^{\mathrm{d}}$ groups, there was no statistical difference in the mean visual acuity either at 6 weeks or at 6 months $(P=0.176$ and 0.414 ,respectively, Mann-Whitney $U$ test), whereas both groups (ELM ${ }^{c} /$ IS-OS ${ }^{c}$ and ELM ${ }^{c} /$ IS-OS $^{d}$ ) separately showed a significantly better visual acuity than the ELM ${ }^{\mathrm{d}} / \mathrm{IS}^{-} \mathrm{OS}^{\mathrm{d}}$ group at 6 months ( $P=0.011$ and 0.009 , respectively), although the corresponding $P$-values at 6 weeks were not statistically significant ( $P=0.477$ and 0.924 , respectively).

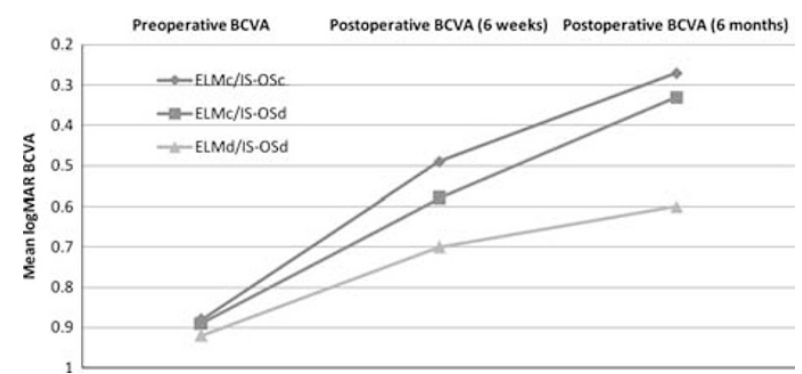

Figure 2 Comparison of preoperative and postoperative logarithms of the minimum angle of resolution (logMAR) and best-corrected visual activity (BCVA) in the three groups at 6 weeks and 6 months (Friedman test, $P=0.08$ and 0.03 , respectively).
The percentage of all patients showing a BCVA improvement of $\geq 2$ lines at 6 months was $71.2 \%$ (40 out of 56). However, a separate analysis for each group showed that the extent of improvement was significantly higher in the ELM ${ }^{\mathrm{c}} / \mathrm{IS}-\mathrm{OS}^{\mathrm{c}}$ and ELM ${ }^{\mathrm{c}}$ / IS-OS ${ }^{\mathrm{d}}$ groups ( $85.7 \%$ and $86.2 \%$, respectively) compared with the ELM ${ }^{\mathrm{d}} / \mathrm{IS}-\mathrm{OS}^{\mathrm{d}}$ group $(40 \% ; P=0.01)$ (Table 2$)$.

When we compared the status of the ELM and IS-OS revealed by SD-OCT, at 6 weeks and at 6 months in the

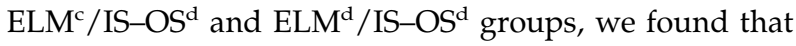
a restoration of the integrity of the IS-OS layer was observed in $51.7 \%$ (15 out of 29) of the eyes in the ELM $^{\mathrm{c}} / \mathrm{IS}-\mathrm{OS}^{\mathrm{d}}$ group, whereas in the ELM ${ }^{\mathrm{d}} / \mathrm{IS}^{-} \mathrm{OS}^{\mathrm{d}}$ group, only $5 \%$ (1 out of 20 ) of the eyes demonstrated continuity of the IS-OS layer at 6 months. This difference was statistically significant $(P=0.001)$ (Table 2 ,

Figures 3 and 4).

\section{Discussion}

The findings of the present study demonstrate the importance of the ELM in restoration of visual function following successful surgical $\mathrm{MH}$ repair. SD-OCT has allowed us to image the foveal microstructural anatomic abnormalities of the outer retina to the extent that we can predict functional recovery with a greater degree of accuracy. Similar to previous reports concerning retinal reattachment, where the integrity of the ELM was identified as a critical parameter for predicting

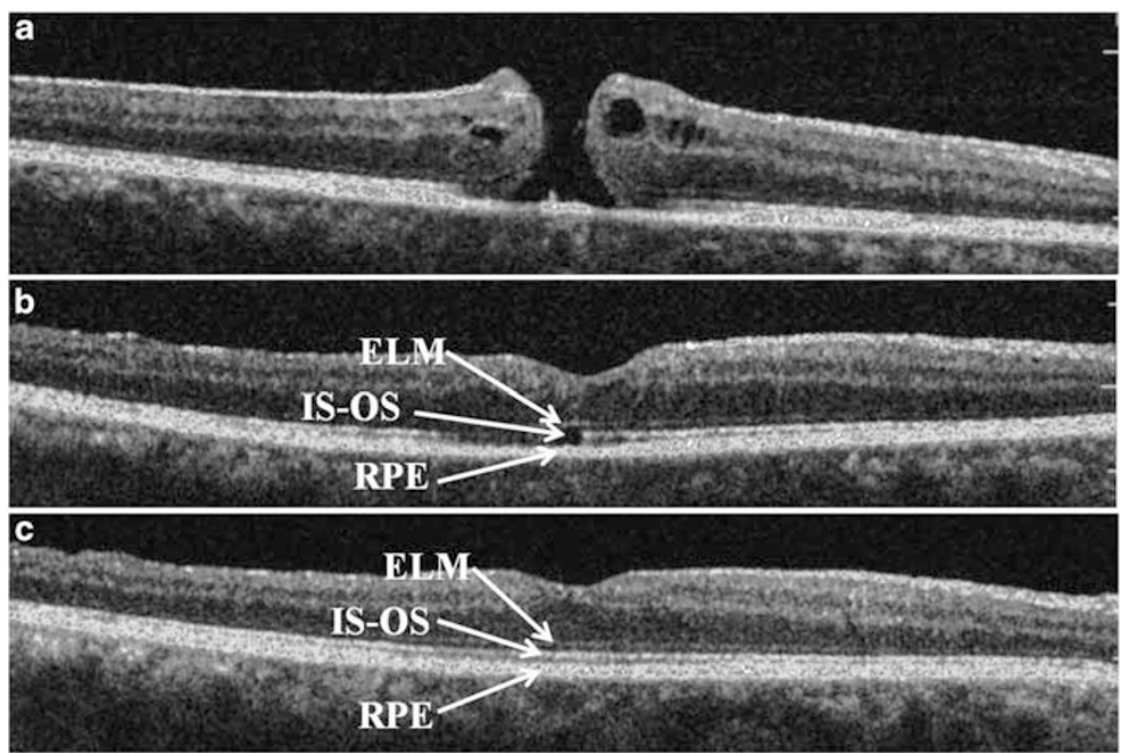

Figure 3 Representative SD-OCT images of a patient from the ELM ${ }^{\mathrm{c}} /$ IS-OS $^{\mathrm{d}}$ group: preoperative (a), postoperative at 6 weeks (b), and 6 months (c). Foveal disruption of the photoreceptor layer is seen at 6 weeks after the surgery, whereas the ELM is continuous above the defect in IS-OS (BCVA 20 out of 60). At 6 months, the IS-OS layer has been completely restored (BCVA 20 out of 30). SD-OCT, spectral domain optical coherence tomography; ELM, external limiting membrane; IS-OS, inner segment-outer segment junction layer; $\mathrm{ELM}^{\mathrm{c}} / \mathrm{IS}^{-} \mathrm{OS}^{\mathrm{d}}$, ELM continuous and IS-OS discontinuous; BCVA, best-corrected visual acuity. 


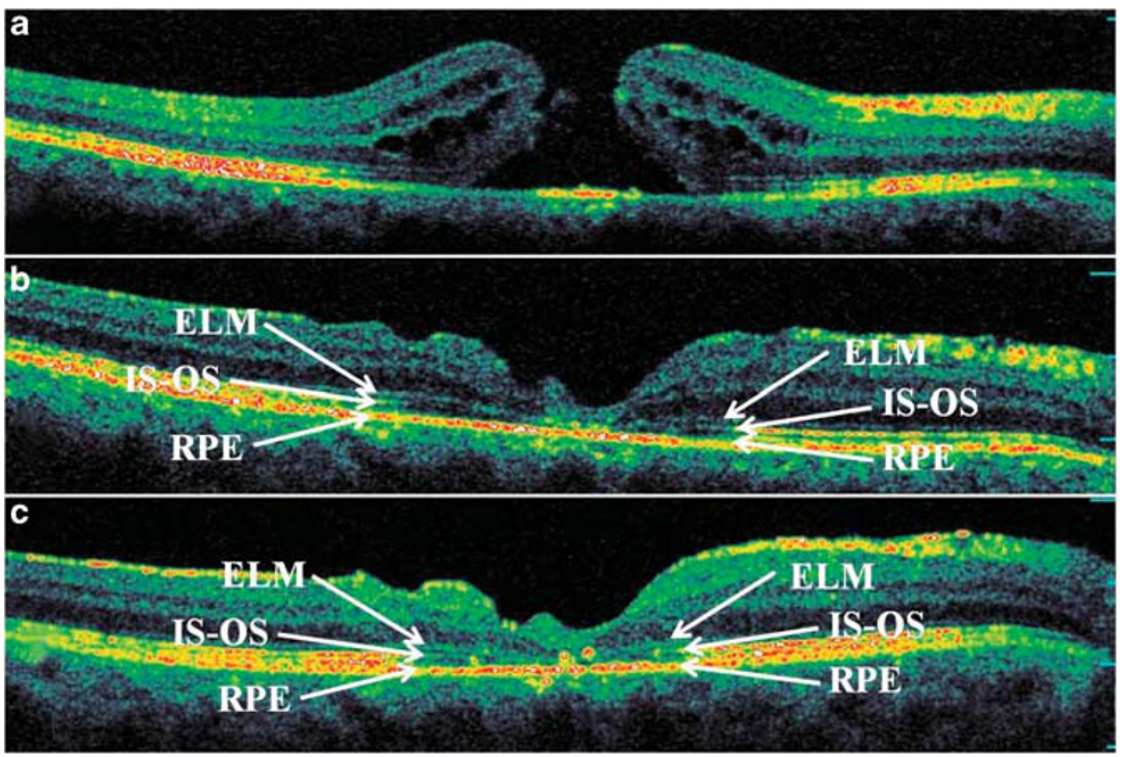

Figure 4 Representative SD-OCT images of a patient from the ELM ${ }^{\mathrm{d}} / \mathrm{IS}-\mathrm{OS}^{\mathrm{d}}$ group: preoperative (a), postoperative at 6 weeks (b), and 6 months (c). Foveal disruptions of both ELM and photoreceptor layer were present at 6 weeks after the surgery (BCVA 20 out of 200). At 6 months, disarrangement of outer retina layers is seen and neither ELM nor IS-OS has been restored (BCVA 20 out of 125). SD-OCT, spectral domain optical coherence tomography; ELM, external limiting membrane; IS-OS, inner segment-outer segment junction layer; $\mathrm{ELM}^{\mathrm{c}}$ /IS-OS ${ }^{\mathrm{d}}$, ELM continuous and IS-OS discontinuous; BCVA, best-corrected visual acuity.

restoration of photoreceptors, ${ }^{8,9}$ our findings suggest that combined disruptions of the ELM and IS-OS junction predict worse visual outcomes for $\mathrm{MH}$ repair than isolated IS-OS disruptions. The findings of this article complement those of Wakabayashi et al, ${ }^{15}$ who, while studying ELM recovery, IS-OS recovery, and visual outcomes following $\mathrm{MH}$ repair, found that early postoperative reconstruction of the foveal ELM helps predict restoration of the foveal photoreceptors and better visual outcomes. Our results may be useful for the insight they provide into the essential components of $\mathrm{MH}$ repair and important prognostic signs in the early postoperative period, particularly ELM status at 6 weeks, which appears to be critical in determining the visual outcome at 6 months.

The work of Bunt-Milam et $a l^{6}$ demonstrated that in addition to providing structural support, the zonular adherentes of the ELM serve to define an important extracellular space within the retina, which can be damaged as MHs develop. The photoreceptors and other neuronal elements are subjected to the atrophic change at the margins of the hole. This may result in glial cell migration to the margin of the developing $\mathrm{MH}$, which subsequently may determine whether the process of $\mathrm{MH}$ resolution following the surgery will be successful or not. ${ }^{16-18}$ Several clinicopathological studies of repaired MHs have shown that centrifugal displacement of photoreceptors from the foveal center, reestablishment of foveal depression, and postsurgical hole closure appear to depend on glial cell proliferation of Müller cells. ${ }^{10-13}$

In some instances of $\mathrm{MH}$ formation, exposed glial cells at the edge of the $\mathrm{MH}$ can migrate across cone outer segments either into a gaping hole or onto the smooth ILM, generating contracting membranes, which can produce faulty apposition and increase the migratory gap. ${ }^{17}$ If glial proliferation and migration, which are supposed to facilitate closure of the foveal defect, become disarranged and disorganized, restoration of a continuous ELM may not occur and successful $\mathrm{MH}$ closure may fail. If Müller cells are unable to support reapproximation of the normal photoreceptors to the central fovea, growth of the normal inner and outer segments may not occur. Previously, it has been demonstrated that normal IS-OS will develop from intact photoreceptor cell bodies in successfully closed MHs. ${ }^{10,16,18}$ However, in our study, similar to the results reported by Wakabayashi et $a l^{9}$ following RD repair, a continuous IS-OS layer was not detected in any eye in the absence of a continuous ELM.

Additionally, akin to the findings in eyes with repaired RDs, ${ }^{9}$ where disrupted ELM and IS-OS on initial examination foretold failure of complete restoration of those lines throughout the follow-up, the results of our study showed that if ELM was not present at 6 weeks, the likelihood of finding continuity of both ELM and IS-OS at 6 months was very low $(5 \%)$. This may be due to 
irreversible damage to either the Müller cells, which are not capable of re-establishing zonular adherentes, or the photoreceptor bodies, which are not competent to generate normal IS-OS. Given that the MH appeared to be closed $24 \mathrm{~h}$ postoperatively in more than a half of the cases and $48 \mathrm{~h}$ postoperatively in three-quarters of the cases, as it was found by Eckardt et al, ${ }^{19}$ it appears safe to assume that a period of $<6$ weeks is the time interval sufficient for the restoration of the ELM.

The findings of the present report and other publications ${ }^{20,21}$ describing SD-OCT findings of successfully closed MHs indicate that ELM can recover or 'heal', by regaining its continuity after $\mathrm{MH}$ surgery. The process of successful reformation of zonular adherentes between inner segments and Müller cells after MH, contributing to the ELM 'healing', appears to be a necessary condition for structural and functional restoration of the impaired photoreceptor layer.

The ability of photoreceptors to recuperate following RD surgery has been previously reported. ${ }^{9}$ Sixty-four percent of the eyes with disrupted IS-OS junction and intact ELM showed complete restoration of the IS-OS junction. ${ }^{9}$ Although the pathogeneses of $\mathrm{MH}$ and RD are different, both diseases are characterized by photoreceptor damage, expressed as disruption of the IS-OS layer seen on SD-OCT. The results of the present study support the explanation, provided by Wakabashi et al, ${ }^{9}$ who assumed that restoration of the outer segments of the photoreceptor layer can occur as long as the degenerative changes have not yet involved the photoreceptor cell bodies.

Although postoperative healing of the IS-OS line varies in successfully closed $\mathrm{MHs}^{22}$ only $12.5 \%$ of the eyes in the present study showed the continuity of the IS-OS on the sixth postoperative week. Analyzing the ELM status, we found that in 36 out of 56 eyes (64.3\%) there was a complete reconstitution of ELM at 6 weeks after the surgery. It is possible that the eyes of the two groups (ELM ${ }^{\mathrm{c}} / \mathrm{IS}-\mathrm{OS}^{\mathrm{c}}$ group and $\mathrm{ELM}^{\mathrm{c}} / \mathrm{IS}-\mathrm{OS}^{\mathrm{d}}$ group) actually represent the same group of eyes in which the ELM is successfully reformed shortly after the surgery, whereas restoration of the IS-OS line may be a more gradual process. Since the restoration of IS-OS may even take more than 1 year, ${ }^{23,24}$ a longer follow-up period may be needed in order to draw a more definite conclusion regarding the final IS-OS restoration. In eyes that recovered continuous ELM, the integrity of the IS-OS junction layer appeared to be restored in 15 additional eyes $(51.7 \%)$ of the ELM ${ }^{\mathrm{c}} /$ IS-OS ${ }^{\mathrm{d}}$ group at the sixth postoperative month.

The findings of the present study highlight the discrepancy between the anatomical and functional success of macular surgery. The percentage of anatomical closure, confirmed by clinical examination and SD-OCT, in the current report was $90.3 \%$, which is similar to results reported elsewhere in the literature..$^{25-29}$ However, SD-OCT analysis of outer retinal restoration may help to shed some light on the reasons for discrepancies in functional outcomes.

Factors that ssem to be important for increasing the chances of ELM restoration and subsequent photoreceptor layer repopulation include mobilization of the wound margins and good tissue apposition. This minimizes the migratory distance across the hole, allowing glial cells access to a migratory surface with a minimum gap. It is achieved by elimination of tangential vitreous traction, providing sufficient supportive surface tension in the form of gas tamponade, and adequate facedown positioning, which ensures stable apposition of critical surfaces. These measures facilitate and ensure the necessary apposition for the critical period when migration and proliferation of glial cells is thought to occur.

Similarly, other previously published studies ${ }^{1-3}$ have identified the integrity of the IS-OS as correlating with the visual outcome. Chalam et $a l^{2}$ reported that all patients who had a postoperative BCVA improvement of $\geq 2$ lines had a continuous IS-OS line on SD-OCT at the fovea. Both quantitative and qualitative correlations between the size of the defect in IS-OS and BCVA have been found. $3,4,23,30$

Although the postoperative integrity of the IS-OS junction layer is considered to be one of the most important predicting factors for visual success, the findings in the ELM ${ }^{\mathrm{c}}$ /IS-OS ${ }^{\mathrm{d}}$ group demonstrated that visual acuity could still improve even in those eyes that showed IS-OS discontinuity at 6 weeks and had a persistent IS-OS discontinuity at 6 months $(48.3 \%$ of the eyes in ELM $^{\mathrm{c}} / \mathrm{IS}_{-} \mathrm{OS}^{\mathrm{d}}$ group), while their ELM layer was restored. There was no difference between the eyes with restored IS-OS and the eyes with disrupted IS-OS at 6 months in the ELM ${ }^{\mathrm{c}} / \mathrm{IS}-\mathrm{OS}^{\mathrm{d}}$ group $(P=0.53)$. The relationship of defects of the IS-OS layer with visual acuity appears to be a bit more complex. In eyes with closed MHs, the size of the IS-OS disruption was not correlated with visual acuity. ${ }^{30}$ In spontaneously closed MHs, visual acuity improved after $\mathrm{MH}$ closure, even though a residual defect in the photoreceptor IS-OS junction layer was still present. ${ }^{31}$

Other factors that could serve as prognostic factors for postoperative visual outcome have been investigated. Some previous reports demonstrated significant correlations of age, preoperative visual acuity, $\mathrm{MH}$ size, and central foveal thickness with postoperative visual outcome, ${ }^{32-36}$ whereas other series showed contradictory findings. ${ }^{2,22}$ A possible reason for these discrepancies may be related to the ELM's potential to recuperate. For example, eyes with larger $\mathrm{MH}$ diameters provided a 
more difficult environment for glial cells to approximate MH margins and rebuild the ELM and IS-OS layer. The findings of this study suggest that early postoperative status of the ELM is an important indicator of postoperative visual outcome. Eyes with discontinuous ELM showed significantly lower BCVA at 6 months and worse BCVA improvement of $\geq 2$ lines, compared with the eyes with restored ELM. The ILM peeling technique may also be a factor that can affect the anatomic and visual outcomes. ILM peeling has a long learning curve and the competence can vary between surgeons. Using a diamond-dusted silicone brush for elevation of the edge of the ILM may cause less surgical trauma to the retina than using an intraocular forceps or a barbed MVR blade; however, the latter instruments may provide a better edge for peeling. Limitations of the current study include its retrospective, non-randomized design, relatively small sample size, and relatively short follow-up period of 6 months. It has been shown elsewhere that as much as 1 year or more may elapse before a normal foveal contour is restored. ${ }^{23}$ An additional limitation of the present paper is the lack of data regarding postoperative lens status and cataract extraction surgeries.

In conclusion, the integrity of the ELM appears to be an essential ingredient for the eventual restoration of the IS-OS layer and achievement of a favorable visual outcome following $\mathrm{MH}$ repair. These findings suggest that further investigation, using a prospective design of a larger patient population with longer follow-up, may be warranted.

\section{Summary}

\section{What was known before}

- The external limiting membrane appears to be another hyper-reflective landmark in the outer retina.

- Although less prominent, the ELM line is distinctive, appearing just above the IS-OS junction hyper-reflective line.

- Photoreceptor cell bodies containing the nuclei and the apical processes of Müller cells are connected by a row of zonular adherents that collectively form the ELM.

- Recent findings in eyes following retinal detachment (RD) repair have shown that combined disruptions of ELM and IS-OS result in worse visual outcomes compared eyes with isolated IS-OS disruptions.

What this study adds

- The findings of this study suggest that early-postoperative status of the ELM is an important indicator of postoperative visual outcome.

- Eyes with discontinuous ELM showed significantly lower BCVA at 6 months and worse BCVA improvement of $\geq 2$ lines, compared with the eyes with restored ELM.

- The integrity of the ELM appears to be an essential ingredient for eventual restoration of the IS-OS layer and achievement of a favorable visual outcome following macular hole repair.

\section{Conflict of interest}

Patricia MT Garcia is a consultant for OPKO/OTI (Miami, FL, USA). Richard B Rosen has received support from the Bendheim-Lowenstein Retinal Fund, the Gladys Brookes Foundation, and is a member of the Scientific Advisory Board of OPKO/OTI. The remaining authors declare no conflict of interest.

\section{References}

1 Baba T, Yamamoto S, Arai M, Suqawara T, Mitamura Y, Mizuova S. Correlation of visual recovery and presence of photoreceptor inner/outer segment junction in optical coherence images after successful macular hole repair. Retina 2008; 28(3): 453-458.

2 Chalam KV, Murthy RK, Gupta SK, Brar VS, Grover S. Foveal structure defined by spectral domain optical coherence tomography correlates with visual function after macular hole surgery. Eur J Ophthalmol 2010; 20(3): 572-577.

3 Inoue M, Watanabe $\mathrm{Y}$, Arakawa A, Sato S, Kobayashi S, Kadonosono K. Spectral-domain optical coherence tomography images of inner/outer segment junctions and macular hole surgery outcomes. Graefes Arc Clin Exp Ophthalmol 2009; 247(3): 325-330.

4 Oh J, Smiddy W, Flynn H, Gregori G, Lujan B. Photoreceptor inner/outer segment defect imaging by spectral domain OCT and visual prognosis after macular hole surgery. Invest Ophthalmol Vis Sci 2010; 51(3): 1651-1658.

5 Villate N, Lee JE, Venkatraman A, Smiddy WE. Photoreceptor layer features in eyes with closed macular holes: optical coherence tomography findings and correlation with visual outcomes. Am J Ophthalmol 2005; 139(2): 280-289.

6 Bunt-Milam AH, Saari JC, Klock IB, Garwin GG. Zonulae adherentes pore size in the external limiting membrane of the rabbit retina. Invest Ophthalmol Vis Sci 1985; 26(10): 1377-1380.

7 Spitznas M. [The fine structure of the so-called outer limiting membrane in the human retina]. Albrecht von Graefes Arch Klin Exp Ophthalmol 1970; 180(1): 44-56.

8 Lai WW, Leung GY, Chan CW, Yeung IY, Wong D. Simultaneous spectral domain OCT and fundus autofluorescence imaging of the macula and microperimetric correspondence after successful repair of rhegmatogenous retinal detachment. Br J Ophthalmol 2010; 94(3): 311-318.

9 Wakabayashi T, Oshima Y, Fujimoto H, Murakami Y, Sakaquchi H, Kusaka $\mathrm{S}$ et al. Foveal microstructure and visual acuity after retinal detachment repair: imaging analysis by Fourier-domain optical coherence tomography. Ophthalmology 2009; 116(3): 519-528.

10 Funata M, Wendel RT, de la Cruz Z, Green WR. Clinicopathologic study of bilateral macular holes treated with pars plana vitrectomy and gas tamponade. Retina 1992; 12(4): 289-298.

11 Madreperla SA, Geiger GL, Funata M, de la Cruz Z, Green WR. Clinicopathologic correlation of a macular hole treated by cortical vitreous peeling and gas tamponade. Ophthalmology 1994; 101(4): 682-686. 
12 Nork TM, Ghobrial MW, Peyman GA, Tso MO. Massive retinal gliosis. A reactive proliferation of Müller cells. Arch Ophthalmol 1986; 104(9): 1383-1389.

13 Rosa Jr RH, Glaser BM, de la Cruz Z, Green WR. Clinicopathologic correlation of an untreated macular hole and a macular hole treated by vitrectomy, transforming growth factor-beta 2, and gas tamponade. Am J Ophthalmol 1996; 122(6): 853-863.

14 Holladay JT. Proper method for calculating average visual acuity. J Refract Surg 1997; 13(4): 388-391.

15 Wakabayashi T, Fujiwara M, Sakaguchi H, Kusaka S, Oshima Y. Foveal microstructure and visual acuity in surgically closed macular holes: spectral-domain optical coherence tomographic analysis. Ophthalmology 2010; 117(9): 1815-1824

16 Frangieh GT, Green WR, Engel HM. A histopathologic study of macular cysts and holes. Retina 1981; 1(4): 311-336.

17 Schubert HD, Kuang K, Kang F, Head MW, Fischbarg J. Macular holes: migratory gaps and vitreous as obstacles to glial closure. Graefes Arch Clin Exp Ophthalmol 1997; 235(8): 523-529.

18 Guyer DR, Green WR, de Bustros S, Fine SL. Histopathologic features of idiopathic macular holes and cysts. Ophthalmology 1990; 97(8): 1045-1051.

19 Eckardt C, Eckert T, Eckardt U, Porkert U, Gesser C. Macular hole surgery with air tamponade and optical coherence tomography-based duration of face-down positioning. Retina 2008; 28(8): 1087-1096.

20 Ko TH, Witkin AJ, Fujimoto JG, Chan A, Roqers AH, Baumal CR et al. Ultrahigh-resolution optical coherence tomography of surgically closed macular holes. Arch Ophthalmol 2006; 124(6): 827-836.

21 Michalewska Z, Michalewski J, Sikorski BL, Kaluzny JJ, Wojtkowski M, Adelman RA et al. A study of macular hole formation by serial spectral optical coherence tomography. Clin Exp Ophthalmol 2009; 37(4): 373-383.

22 Sano M, Shimoda Y, Hashimoto H, Kishi S. Restored photoreceptor outer segment and visual recovery after macular hole closure. Am J Ophthalmol 2009; 147(2): 313-318 e311.

23 Christensen UC, Kroyer K, Sander B, Larsen M, la Cour M. Prognostic significance of delayed structural recovery after macular hole surgery. Ophthalmology 2009; 116(12): 2430-2436.

24 Lee JE, Lee SU, Jea SY, Choi HY, Oum BS. Reorganization of photoreceptor layer on optical coherence tomography concurrent with visual improvement after macular hole surgery. Korean J Ophthalmol 2008; 22(2): 137-142.

25 Alpatov S, Shchuko A, Malyshev V. A new method of treating macular holes. Eur J Ophthalmol 2007; 17(2): 246-252.

26 Bainbridge J, Herbert E, Gregor Z. Macular holes: vitreoretinal relationships and surgical approaches. Eye (London, England) 2008; 22(10): 1301-1309.

27 Haritoglou C, Gass CA, Schaumberger M, Gandorfer A, Ulbig MW, Kampik A. Long-term follow-up after macular hole surgery with internal limiting membrane peeling. Am J Ophthalmol 2002; 134(5): 661-666.

28 Kim SS, Smiddy WE, Feuer WJ, Shi W. Outcomes of sulfur hexafluoride (SF6) versus perfluoropropane $(\mathrm{C} 3 \mathrm{~F} 8)$ gas tamponade for macular hole surgery. Retina 2008; 28(10): 1408-1415.

29 Kumagai K, Furukawa M, Ogino N, Larson E, Uemura A. Long-term outcomes of macular hole surgery with triamcinolone acetonide-assisted internal limiting membrane peeling. Retina 2007; 27(9): 1249-1254.

30 Chang LK, Koizumi H, Spaide RF. Disruption of the photoreceptor inner segment-outer segment junction in eyes with macular holes. Retina 2008; 28(7): 969-975.

31 Privat E, Tadayoni R, Gaucher D, Haouchine B, Massin P, Gaudric A. Residual defect in the foveal photoreceptor layer detected by optical coherence tomography in eyes with spontaneously closed macular holes. Am J Ophthalmol 2007; 143(5): 814-819.

32 Apostolopoulos MN, Koutsandrea CN, Moschos MN, Alonistiotis DA, Papaspyrou AE, Kyriaki TE et al. Evaluation of successful macular hole surgery by optical coherence tomography and multifocal electroretinography. Am J Ophthalmol 2002; 134(5): 667-674.

33 Gupta B, Laidlaw DA, Williamson TH, Shah SP, Wong R, Wren S. Predicting visual success in macular hole surgery. Br J Ophthalmol 2009; 93(11): 1488-1491.

34 Ip MS, Baker BJ, Duker JS, Reichel E, Baumal CR, Gangnon $\mathrm{R}$ et al. Anatomical outcomes of surgery for idiopathic macular hole as determined by optical coherence tomography. Arch Ophthalmol 2002; 120(1): 29-35.

35 Ruiz-Moreno JM, Staicu C, Pinero DP, Montero J, Lugo F, Amat P. Optical coherence tomography predictive factors for macular hole surgery outcome. Br J Ophthalmol 2008; 92(5): 640-644.

36 Ullrich S, Haritoglou C, Gass C, Schaumberger M, Ulbig MW, Kampik A. Macular hole size as a prognostic factor in macular hole surgery. Br J Ophthalmol 2002; 86(4): 390-393. 